eISSN: 2659-6482

DOI: https://doi.org/10.14201/pmrt.20624

\title{
JONNY GREENWOOD, LA INMERSIÓN PERFECTA EN EL CINE DE PAUL THOMAS ANDERSON
}

\author{
Jonny Greenwood, the Perfect Immersion in the Cinema of \\ Paul Thomas Anderson
}

\section{José SÁNCHEZ SANZ}

Universidad Europea de Madrid

joseantonio.sanchez@universidadeuropea.es

RESUMEN: El agotamiento del lenguaje de la música de cine corre en paralelo al del propio lenguaje cinematográfico tradicional. En un tiempo en el que la proliferación de plataformas para consumo de productos audiovisuales lo ha diversificado, y en el que la asunción de nuevos medios ha cambiado la forma de contemplar imágenes en movimiento, son necesarios cambios estéticos. Un cineasta como Paul Thomas Anderson todavía confía en formas cercanas a la tradición, aunque siempre las ponga en cuestión en sus películas. Generar lo nuevo desde la base tradicional es la forma más original de enfrentarse a esos cambios necesarios para que un nuevo cine cautive al cinéfilo y a cualquier persona que necesite que le cuenten una historia de forma sólida. La música de Jonny Greenwood cumple con precisión ese objetivo desde el acompañamiento narrativo de la acción. La orquesta tradicional se funde en nuevas sonoridades tomadas de un lenguaje contemporáneo que tampoco quiere abandonar las maneras de una forma abrupta. Por un lado, un paso atrás, en un entorno actual con un lenguaje de la música de cine muy dependiente de la maquinaria, por otro lado, un paso adelante en un estilo muy lejano al gran mainstream musical al recuperar sonidos originales, así como el cine de Paul Thomas Anderson rescata emociones perdidas en el cine actual.

Palabras clave: Música; cine; Paul Thomas Anderson; Jonny Greenwood; música contemporánea; nuevos cines. 
ABSTRACT: The depletion of the film music language runs parallel to the traditional film language. In a time in which the proliferation of platforms for consumption of audiovisual products has diversified it, and when the assumption of new media has changed the way of contemplating moving images; aesthetical changes are needed. A filmmaker like Paul Thomas Anderson still relies on traditional parameters, although he always puts them in question in his films. Create a new feature from the traditional base is the most original way to face those changes that are necessary for a new cinema that captivates the cinephile and all those who needs a solid story on the screen. Jonny Greenwood's music fulfills accurately that objective starting on the narrative accompaniment of the action. The traditional orchestra plays new sounds taken from a contemporary language that does not want to leave the tradition. On the one hand a step back, the current language of film music relies so much on machinery; on the other hand, a step forward in a style very far from the great musical mainstream that recovers original sounds, as well as the films made by Paul Thomas Anderson rescues lost emotions in today's cinema.

Keywords: Music; film; Paul Thomas Anderson; Jonny Greenwood; contemporary music; new cinemas.

Nos encontramos en la actualidad ante un momento en el que las peores pesadillas descritas en sus textos por Theodor W. Adorno están llegando a materializarse justamente gracias a ese elemento que el pensador alemán tanto criticaba como es la reproducción mecánica que genera una cultura de masas (Adorno, 2007, p. 11). La serialización de productos listos para el consumo y la obtención de beneficios por medio de su comercialización masiva es la actualidad de la producción cultural, todo apoyado por grandes operaciones de marketing y mediáticas que dejan poco espacio para la decisión, sobre todo si esta es artística. El cine llamado comercial copa las pantallas de las salas a nivel mundial con los productos que la factoría de Hollywood decide imponer al público general. Mientras tanto, las opciones más experimentales y creativas quedan relegadas a salas marginales en las que pequeñas audiencias cinéfilas pueden disfrutar, cada vez menos, de propuestas que surgen de una idea de la cultura muy alejada del ideal de rentabilidad que devora nuestra actualidad en todos los campos de nuestro entorno.

A pesar de este escenario casi apocalíptico, existen propuestas que aportan novedad y que proponen una evolución de la música cinematográfica que le sacan del estancamiento en los usos tradicionales convertidos en mantras tecnológicos. 
Una música escrita para acompañar a imágenes contemporáneas utilizando recursos actuales para conseguir dicho fin. Propuestas que van desde la electrónica pura y sus combinaciones con otros estilos, así como la vanguardia, que desde tiempos remotos han sido marginados en la música cinematográfica y limitados a momentos de inquietud y tensión. Dentro de este segundo grupo se encuentra el trabajo del compositor Jonny Greenwood, figura peculiar en el entorno de la música contemporánea. Conocido por su labor como guitarra y compositor de la banda británica Radiohead, su cara menos conocida hasta hace poco era la de compositor de música de concierto. Esa faceta fue la que llamó la atención del director de cine Paul Thomas Anderson para iniciar una relación artística con él que se ha mantenido durante cuatro películas. Anderson se caracteriza por ser uno de los directores de cine actuales que ha conseguido, a lo largo de una extensa carrera, innovar en el lenguaje cinematográfico hacia una apuesta muy personal que ha sido aceptada por el gran público y la crítica. Su colaboración con Greenwood ha proporcionado una nueva vía para concebir la música cinematográfica desde una posición contemporánea. La combinación entre un cineasta que arriesga en los usos del lenguaje, ya sea narrativamente o visualmente, y un músico en constante evolución que busca sonoridades nuevas para acompañar a las imágenes, ha dado como resultado cuatro películas que necesitan de un análisis para descubrir posibles salidas creativas para una música cinematográfica que quiera apartarse de los usos rutinarios y los clichés que la caracterizan en la actualidad. Teniendo en cuenta la cantidad de matices que la música de Greenwood aporta a estas películas, el análisis resultante que se realizará en este artículo será un punto de partida en el que se extraerán una serie de claves para entrar posteriormente a desarrollarlas en profundidad en trabajos posteriores.

\section{INNOVAR EN LA MÚSICA CINEMATOGRÁFICA}

Ya un pionero de la música para cine como Miklós Rozsa disfrutaba cuando un proyecto le permitía innovar en el lenguaje musical. Esto le pasaba cuando trabajaba en películas que pertenecían al género negro, que en aquel entonces comenzaba a desarrollarse en la industria de Hollywood aportando nuevos usos cinematográficos adaptados a unos relatos que se salían de los esquemas convencionales. Él se sentía cómodo porque le permitía componer como lo hacía antes de entrar a trabajar en cine («go back to my earlier self») (Porfirio, 2002, p. 167). La historia de este compositor está plagada de conflictos con los productores que consideraban sus partituras demasiado complejas para lo que el público solicitaba. Conflictos que siempre eran resueltos gracias a la ayuda de los directores de los proyectos, más centrados en ideas creativas y que en aquel entonces disponían de una mayor capacidad de decisión que en épocas anteriores. Y demostraron que 
se equivocaban, las músicas que Rozsa compuso para acompañar esas películas se han trascendido a la historia del cine.

Adorno observaba el origen de barraca de feria del cine como espectáculo, por lo que; «solamente a través del shock puede el cine conseguir que la vida empírica, que dice reproducir en virtud de sus inherentes virtudes técnicas, aparezca como algo extraño que permita reconocer la esencia que late bajo la superficie reproducida realísticamente» (Adorno, 2007, p. 42). Esa esencia no era posible de desarrollar en un cine comercial plenamente heredero «de ese arte popular de los cuentos de miedo y las novelas por entregas que no superan los patrones establecidos por el arte burgués» (Adorno, 2007, p. 42). A pesar de que las palabras de Adorno están escritas en una época que queda muy lejana, el cine ha mantenido esta dependencia de las formas de relato criticadas por el filósofo alemán. Royal S. Brown (2009, p. 236) propone que los grandes desarrollos más interesantes que han tenido lugar en los últimos veinte o treinta años en el área de la música cinematográfica se refieren más al campo de la filosofía y de la ontología de la imagen que en las evoluciones que han tenido lugar en el arte de la composición de la música para cine. Podría ser esta una posibilidad, pero entraríamos en el terreno de un cine marginal destinado desde su concepción a atraer a minorías. A pesar de ello, es posible buscar la posibilidad de encontrar ese punto en el que la música no sería un mero sostén emocional y se integre en la narrativa como sustancia significante como factor ontológico de la propia película.

\section{LA NECESIDAD DE LA MÚSICA EN EL CINE DE PAUL THOMAS ANDERSON}

Muy pocos directores dentro del panorama del Hollywood actual pueden disfrutar de tan amplio reconocimiento con películas que sostienen una apuesta tan personal y creativa, como es la de Paul Thomas Anderson. Continuador de una tradición de cineastas estadounidenses, fue capaz de reinventar ese lenguaje heredado y convertirlo en una forma de narrar única que pocos directores pueden replicar. Nombres como Robert Altman, Martin Scorsese, François Truffaut o John Cassavetes, aparte de su mentor Jonathan Demme, son algunos de los nombres que se relacionan con su manera de hacer cine (Montero, 2011, capítulo 1 , sección 8 , párrafo 2). Su compromiso con las historias que cuenta le llevan a tener un control alto de todas las fases de la creación cinematográfica. Las que están bajo su mano, guion y dirección, son en las que mejor se desarrolla, para el resto utiliza a personas de confianza que puedan aportarle aquello que él busca.

En lo referente a la música de sus películas Anderson siempre la ha tenido muy presente tanto incidental como temas sincronizados. Es quizá esa la razón por la que en las primeras trabaja con músicos como Jon Brion o Michael Penn, que 
provienen más del mundo de la música popular que de la música de concierto o de la especialización en música de cine. Es notable el interés que Anderson tiene por la música, y en sus películas queda claro que indica a sus colaboradores la forma de conseguir el efecto que necesita en el momento necesario. En los proyectos que realizó previos a la colaboración con Jonny Greenwood, la música está presente en algunos casos desde la escritura, como sucedió en Boogie Nights (1997) o Magnolia (1999). Las canciones que sincronizó en ambas son las que escuchaba mientras escribía su guion (Montero 2001, capítulo 4, sección 5, párrafo 5). Por lo tanto, venían ya definidas mucho antes de su inclusión en la fase de montaje. Quizá el proyecto acometido a nivel musical más ambicioso de Anderson fue Magnolia, una película con un guion complejo que abarca a muchos personajes con tramas enlazadas en una tela de araña que recuerda a las películas de uno de sus directores más admirados, Robert Altman (Toles, 2016, capítulo 5, sección 1, párrafo 3). La partitura es orquestal, promesa que Anderson tenía guardada a Brion tras componer la música de su primera película, Hard Eight, Sidney (Hard Eight, 1996), y que consideraba que era una forma de que la música estuviese a la altura de la película (Montero 2001, capítulo 4, sección 5, párrafo 18). La función que cumple es la de crear nexos de unión entre los personajes y continuidades en la acción, así como lo hacen las canciones de Aimee Mann sincronizadas en ella. La complejidad de una trama tan dispersa necesitaba claramente una ayuda para el espectador que le sirviese de guía en el laberinto que se convierte el argumento.

La experiencia de Jonny Greenwood en el cine previa a su trabajo con Anderson fue la composición para la película experimental Bodysong (Simon Plummell, 2003). Con este trabajo llamó la atención del director para plantearse la posibilidad de su colaboración en el siguiente proyecto que tenía en mente. El elemento decisivo para ya contactarle será cuando escuche su obra orquestal, realizada para la BBC, Popcorn Superhet Receiver (2004), fascinado por su sonido (Montero 2001, capítulo 4, sección 5, párrafo 25). A partir de ahí se generará una relación que hasta el momento se ha mantenido durante 4 películas; Pozos de ambición (There Will Be Blood, 2007), The Master (2012), Puro vicio (Inherent Vice, 2014) y El hilo invisible (Phantom Thread, 2017). Las partituras que Greenwood compone para estas cuatro películas se mantienen dentro de un lenguaje contemporáneo adaptándose a la trama de cada una de ellas. La impronta que dejan en la música para cine es importante, ya que ese lenguaje utilizado no suele ser común en películas comerciales de una forma tan intensiva. Son sobre todo las dos primeras, Pozos de ambición y The Master, en las que Greenwood se libera de toda referencia a la tradicional visión de la música de cine y plantea partituras que no solamente innovan en cuanto al lenguaje puramente musical, también, y en esto tiene mucha importancia su colaboración con Anderson, presentan nuevas formas para acompañar la imagen que huyen de prácticas tradicionales, consideradas casi paradigmas dentro de la música cinematográfica. En las dos últimas películas Puro vicio y El 
bilo invisible la música de Greenwood mantiene ese lenguaje, pero queda menos liberado por la forma de narración y las referencias sobre las que han sido construidas ambas. En la primera, el tono a película de suspense con ligeros toques a la manera de Bernard Herrmann aportan un ambiente serio que contrasta con el disparatado argumento. En la segunda, claramente Anderson intenta reflejar, utilizando un apoyo importante en la música, un mundo de glamour que envuelve a los dos protagonistas y que contrasta con su conflictiva relación. A pesar de estas referencias, la labor de Greenwood no se ha visto limitada y ha seguido apostando por la apuesta que le ha caracterizado como compositor de música para cine.

\section{UNA FORMA ÚNICA DE COMPONER MÚSICA PARA CINE}

El uso de un lenguaje articulado por técnicas provenientes de la música contemporánea aporta nuevas sonoridades que renuevan el sonido de la música cinematográfica, pero son también innovadores los usos que entre Anderson y Greenwood le dan a esta música. Según Adorno (2007, p. 45), los lenguajes musicales actuales aportan a la música cinematográfica nuevas dimensiones expresivas, ampliando el espectro de emociones posibles, desde los más extremos a los más neutros. Pero no solamente es en el lenguaje musical en lo que se produce la innovación que Greenwood aporta a la música de cine; esta se encuentra, sobre todo, en la integración de la música dentro de la película. Salvo en El bilo invisible, que goza de una partitura extensa, el resto de las analizadas se caracterizan por una economía en cuanto a música se refiere. Anderson quiere que la música aparezca en los momentos necesarios y que transmita sus mensajes de forma efectiva. El planteamiento podría integrarse dentro de un concepto global de la banda sonora en el que tanto las canciones sincronizadas, como las voces y los sonidos se comunican y se genera así una fusión similar a la que se produce entre todos los elementos visuales. Dos campos independientes que abarcan dos sentidos en los espectadores, que se conducen en paralelo pero que son comprendidos de forma conjunta. El resultado de la colaboración entre director y músico es un trabajo de composición único, con mucha personalidad. Un lenguaje original que a su vez se convierte en difícil de imitar, ya que está demasiado imbricado con el relato al que acompaña. Teniendo en cuenta que el análisis profundo de todas las películas supondría una amplia extensión que no sería posible en un artículo de estas características, se procederá a definir cuáles son los puntos de innovación coincidentes más destacables entre las cuatro y servir así de punto de partida a posteriores investigaciones. 


\section{LA MÚSICA SE FUNDE CON EL RESTO DE ELEMENTOS DE LA BANDA SONORA}

En la mayor parte de las películas en las que Anderson y Greenwood colaboran, el sonido es muy importante, como sucede en el cine actual. En las películas anteriores a esta colaboración también el sonido era clave, pero el tipo de música que Greenwood aporta favorece que la música tenga cierta relación con los ambientes sonoros, llegando en algunos casos a fundirse con ellos. En muchos de los casos existe una comunicación entre música y sustancia sonora que crea significaciones y metáforas que de otra forma no podrían ser percibidas. La película en la que se desarrolla más esta función es Pozos de ambición. En esta película, los sonidos relacionados con el petróleo y su extracción de la tierra siempre están presentes cual si fuera un tipo de leitmotiv que representara el eje central de la narración; un personaje no humano que vehicula la ambición de los dos protagonistas y que les llevará a los sucesivos conflictos que les enfrentará a lo largo de todo el metraje. Los sonidos de los bidones, del gas al salir y del petróleo recorriendo la tierra son elementos que muestran de forma velada la cara oculta de Daniel Plainview en su afán extractor del espíritu de la tierra en beneficio de su ambición capitalista. En uno de los momentos clave de la película, el accidente que sufre su hijo H. W. que le provocará la sordera que será la causa de que Daniel comience a levantar distancias entre ambos, se produce una comunicación perfecta entre música y sonido. El diseño sonoro del momento de la explosión está basado en el uso habitual dentro del realismo pretendido en la banda de sonido. En los planos en los que la acción se focaliza sobre el personaje de H. W. el sonido nos descubre la sordera que se le ha provocado al personaje por medio de su amortiguación. La carrera desesperada de Plainview para rescatar a su hijo sigue siendo acompañada de los sonidos del accidente que son tan fuertes que obliga a los personajes a gritar. El operario ayuda a que tome el niño en brazos y se dirige corriendo hacia la oficina para poder socorrerlo. Es en el plano general, ya tomado desde un punto de vista lejano al pozo, donde el estruendo es menor, cuando comienza a sonar una música que mezcla percusiones rítmicas, que marcan de forma irregular, con movimientos de cuerdas rápidos que forman clusters dinámicos. Es casi como si esa música fuese una regularización temporal de los ruidos del pozo. Parece como si los bidones, sonido que está presente gran parte de la película, volviesen a cantar, pero esta vez de un modo rítmico, musical. El pozo va a separar a ambos personajes al considerar Plainview que H. W. se ha convertido en un inválido, incapaz de continuar con su legado. La música hace que el pozo cobre protagonismo en esta acción y muestre su cara más terrible contra Daniel Plainview. Su fuente de beneficio se convierte a su vez en su fuente de drama.

Otro caso de fusión entre la música y los elementos sonoros se encuentra en la misma película en un momento anterior pero dirigido hacia otra sustancia narrativa. 
Tras el primer conflicto entre Eli Sunday y Daniel Plainview, protagonistas del duelo que impulsa la narración de la película, arranca un bloque de música con ciertas peculiaridades. El cierre de un trato injusto entre la familia Sunday y el ambicioso industrial petrolero deja a Eli desconcertado y a Plainview crecido ante su aplastante victoria sobre gente humilde a la que puede manejar y presionar a su antojo. Es el momento en el que ambos personajes van a estrecharse las manos cuando Eli no le estrecha la derecha como le ofrece Plainview, le da la izquierda, dejando a este último sorprendido. Eli coge con la mano derecha la de su hijo H. W. y agacha la cabeza con intención de unir a los tres en oración como agradecimiento. Plainview, ya consciente de la intención de Eli agacha la cabeza con él. En ese momento comienzan a sonar unas cuerdas en pizzicato que repiten una fórmula a la manera de ostinato que va a conducir la acción a la siguiente secuencia. Esa música acompaña al espíritu insaciable de Plainview mientras entra en una agencia inmobiliaria para estudiar la forma de adquirir todas las propiedades posibles dentro de ese territorio. Justo en el cambio, la cuerda abandona el pizzicato y comienza a tocar con arco aumentando la frecuencia de repetición de cada nota, lo que podría asemejarse al sonido de una locomotora, la que encarna a Plainview y que avanza sin freno hacia la obtención del máximo beneficio. La secuencia en la agencia inmobiliaria termina y arranca la siguiente; Plainview se dirige en su coche a la estación de tren para recibir al equipo que le va a apoyar en su labor extractora del petróleo de esas tierras que ha conseguido a base de casi extorsionar a sus habitantes. La música va a tardar en arrancar sobre el plano picado en el que contemplamos la estación al fondo. Es el primer atisbo de tren en el plano el que da el punto de arranque para la música, que recupera ese ostinato que recuerda el sonido de una locomotora solo que en este caso la música se sincroniza con el sonido diegético de la real que entra en imagen. Podría hablarse en este caso del término acuñado por Rick Altman audio-dissolve, cuando sonido diegético y no diegético se funden en una sola sustancia con la intención de crear un nuevo significado (Chion, 1997, p. 194). La música en este bloque realiza una función bastante habitual en su acompañamiento cinematográfico, la de dar continuidad a diferentes secuencias que suceden en tiempos y en espacios distintos pero que están integradas por un mismo espíritu. Es la ambición de Plainview que como si se tratara de una locomotora actúa de forma rápida, ágil y avasalladora. El final del bloque y la fusión de la cuerda con el sonido diegético de la locomotora nos descubre una forma de metáfora cinematográfica que la música nos avanza. Ese tren se convierte en un personaje no humano que representa una emoción, un sentimiento que quedaría oculto a los espectadores si no fuese porque la música lo destaca. 


\section{LA MÚSICA COMPUESTA Y LAS SINCRONIZACIONES SE COMUNICAN}

Paul Thomas Anderson es un director que gusta de utilizar en sus películas músicas sincronizadas, es decir, aquellas que no han sido compuestas expresamente. Canciones que van desde el pop, como son las de Aimee Mann en Magnolia, la música clásica tradicional, como el Concierto para violín de Brahms que aparece en varios momentos en Pozos de Ambición, o los temas de jazz interpretados por Oscar Peterson y su banda en El hilo invisible, son ejemplos claros de su utilización. La intención del uso de estas sincronizaciones por parte de Anderson es doble; por un lado, intenta encuadrar la historia, ya no solo por la época, también para reflejar el ambiente en el que se desarrolla la acción; y por otro, vaciar esas músicas de su significado original al complementarlas con los elementos audiovisuales a los que acompaña. Anteriormente a su colaboración con Greenwood, Anderson demostró que una sincronización podía tener un altísimo peso narrativo, como sucedía en el caso del uso de la canción «Wise Up» en la película Magnolia. El violento arranque del concierto para violín de Brahms refleja la energía destructora de Daniel Plainview y es la música que, tras aparecer en otros momentos acompañando el triunfalismo del personaje, cierra la historia tras su violenta y trágica conclusión. Las versiones de Oscar Peterson, que confunden los espacios diegético y no diegético, al partir la mayor parte de las veces de fuentes presentes en la acción para posteriormente acompañar desde la capa over de la banda sonora, proporcionan el ambiente social perfecto en el que desarrollan los dos personajes protagonistas su particular lucha de clases en la que se ven imbuidos. Anderson contempla las sincronizaciones como una parte importante de la música de la película y apoyan su forma de narrar. Este detalle nos descubre a un director que tiene una visión global de su labor y que está pendiente de todos los detalles que le conduzcan a obtener el resultado que quiere transmitir a la audiencia que va a ver sus películas al cine.

En la primera colaboración entre Greenwood y Anderson, Pozos de ambición, queda patente, por la forma en cómo se utiliza, que una parte de la música del primero ha sido sincronizada. La partitura contemporánea compuesta por el guitarra de Radiohead que llamó la atención de Anderson para iniciar su colaboración, Popcorn Superbet Receiver, aparece sincronizada en algunos momentos aportando elementos expresivos de gran importancia. La diferencia entre utilizar una música sincronizada y una compuesta para la película es que la primera no está referida a la imagen. Entonces es el montaje el que tiene que ajustarse a ella. La impresión que da su uso en las películas de Paul Thomas Anderson es de que camina en paralelo a la imagen sin buscar fijar unas sincronías salvo en momentos muy concretos. Es por ello que los bloques de música son largos, dejan espacios para la respiración del acompañamiento y crean ambientes expresivos que se 
continúan entre varias secuencias en las que la emoción progresa, a pesar de cambios de tiempo o de localización. La música de Greenwood en el resto de películas en las que ha colaborado con Anderson es de un carácter similar. Los bloques son largos, se extienden sobre varias secuencias y se mueven a su propio ritmo, sin subrayar elementos de la acción. Un movimiento en paralelo a la imagen para que su cometido sea el de definir un ambiente que queda oculto a la percepción de los espectadores pero que es necesario para la comprensión del conjunto. Uno de los ideales que Adorno (2007, p. 34) contemplaba como necesarios para que la música de cine enfatice el sentido de la secuencia en lugar de entrar en la convención de imitar la acción visual.

Las sincronizaciones aportan detalles a la composición de la partitura, de forma que la música de Greenwood se integra con ellas sin perder la personalidad creativa del compositor. Es difícil diferenciar la música incidental de las sincronizaciones ya que aportan en algunos momentos significados similares, la diferencia con la incidental es que no se queda en la superficie y penetra hacia el interior de la narración. La instrumentación es uno de los elementos en los que se percibe esta comunicación. Hablar de música orquestal como la única música de cine, o la más posible, es un error en una época actual en la que los caminos se abren en muchas direcciones. La instrumentación es el elemento más cambiante en las colaboraciones entre Jonny Greenwood y Paul Thomas Anderson, aunque siempre se mantiene la base orquestal, aunque sea reducida. La música de cada una de las películas destaca por el uso de un instrumento o de un grupo instrumental que caracterizan toda la partitura. En algunas de ellas, la música compuesta por Greenwood se deja influir por los instrumentos que aparecen de forma dominante en los temas sincronizados. Estas variaciones en la instrumentación aportan a cada partitura una unicidad que las diferencias del resto, pero sin que Greenwood pierda personalidad como compositor.

En el caso de Pozos de Ambición, la orquesta de cuerda es la protagonista de la orquestación. Popcorn Superbet Receiver, la obra de Greenwood sincronizada en varios momentos de la película, está compuesta para esa formación. El resto de la partitura va a utilizar esta agrupación instrumental y un lenguaje musical similar, lo que aporta unidad a toda la partitura. En The Master, al grupo de cuerda se le suma una agrupación instrumental también orquestal, el viento madera. En este caso, no se puede decir que haya un protagonismo de este grupo, aunque en gran parte de la partitura ocupa un lugar predominante. En varios bloques escuchamos flautas y clarinetes en solo, lo que aporta una sonoridad que separa esta partitura de la compuesta para la película anterior. Este es el único caso en el que las sincronizaciones no han influido para la orquestación, más bien parece como que los instrumentos de viento madera se ajustan más con el ambiente general de la película y la época en la que tiene lugar. Esta instrumentación suele aparecer en 
los momentos en los que nos sumergimos en el ambiente sofisticado que rodea a Lancaster Dodd, su familia y sus seguidores, pertenecientes todos ellos a la alta sociedad estadounidense. En Puro Vicio, la guitarra eléctrica es el instrumento dominante en la música incidental, así como lo es en la mayor parte de las canciones sincronizadas en la película en el estilo rock de la época. La languidez del sonido de esta guitarra nos refleja tanto la decadencia de su protagonista, Doc Sportello, como la del mundo que le rodea. En El hilo invisible, el piano es el instrumento que sobresale sobre el resto cobrando un alto protagonismo. Un piano que suena a veces romántico e impresionista, como los temas de Fauré y Debussy sincronizados en la película, y otras en un estilo jazz sofisticado, como los temas interpretados por Oscar Peterson o Duke Ellington que también están presentes en la banda sonora. Ese piano a veces suena limpio y brillante, mostrando el lujo y la sofisticación del entorno en el que se desarrolla la historia, pero otras suenan roto, atascado, como si fuese preparado por elementos que se sitúan entre sus cuerdas aportando de esta forma la capa de oscuridad que envuelve a ambos personajes. Salvando las cuerdas, presentes en todas las partituras, el resto de instrumentos mencionados no aparecen en las demás películas, fijando así una exclusividad para cada una de las historias. Podría decirse de estos usos que son una mera curiosidad, pero la idea de darle a un instrumento la función identificadora de cada una de las películas adquiere una trascendencia importante desde un punto de vista narrativo. Cada instrumento no es escogido meramente por azar, tiene un alto poder de significación, se convierten en significantes que completan el gran mural expresivo que son las películas de Paul Thomas Anderson.

\section{EL LEITMOTIV SE REINVENTA}

El leitmotiv es uno de los elementos más importantes y más representativos de la música cinematográfica. Importado de la ópera del siglo XIX, fue implantado en la composición de música para cine por los primeros compositores que empezaron a trabajar en el Hollywood de los años 30. Adorno (2007, p. 16) hablaba despectivamente de su uso en exceso en el cine como de una «marca registrada en la que se podían reconocer figuras, sentimientos y símbolos». Su crítica se centra en el contraste de su concepción como elemento preciso que necesita ser desarrollado dentro de «un campo musical amplio que lo dote de un sentido compositivo que supere la mera función de indicador». Adorno achaca al realismo que presentan las imágenes cinematográficas y al montaje, la deficiencia que se produce en sus usos aplicados al cine, de tal forma que un recurso como el leitmotiv no pueda desarrollarse así al igual que lo hacía en las óperas de Wagner. El montaje fragmenta y dispersa los leitmotiv de tal forma que se convierten en mera ilustración de ideas perdiendo la esencia simbólica que disfrutaba en la ópera del compositor alemán; «según la propia concepción Wagneriana, debe además 
elevar la acción escénica hasta la esfera del significado metafísico. En el ciclo del anillo, cuando Wagner hace que el motivo de Walhalla resuene en las tubas, no lo hace para indicar el lugar de residencia de Wotan, sino para expresar la esfera de lo sublime. De la voluntad universal, del principio original» (Adorno, 2007, p. 17). Ese sentido metafísico no puede tener lugar en un medio fragmentario y realista como el cine. La colaboración entre Anderson y Greenwood puede llegar a verse dentro de esta nueva dimensión, ya que conciben la música como una parte esencial de la película imposible de ser separada de las propias imágenes. Es en esta concepción del cine como un espectáculo en el que las sustancias significativas se comunican, cuando el leitmotiv puede ocupar un lugar que se separe del simple puntero que señala automáticamente las emociones para ser percibidas por el público de forma automática.

La película Pozos de Ambición arranca con una larga secuencia de escenas en la que vemos los orígenes de Plainview como hombre hecho a sí mismo luchando contra la tierra, de la que pretende extraer la riqueza que más adelante le desbordará. El acompañamiento musical de esta secuencia es un largo cluster de cuerda que crece y se deshace como si se tratara de una respiración. Este cluster, extraído del tema Popcorn Superhet Receiver, en el disco que se comercializó del score de la película se titula Henry Plainview (Walls, 2011), el nombre del falso hermano del protagonista. A pesar que en el disco se le asigna un personaje, el uso que Anderson hace de este tema se extiende a lo largo de gran parte de la película y sobre todo ambienta esta primera parte en la que las imágenes transcurren sin diálogo. El sufrimiento de Plainview en su lucha contra la tierra se presenta crudo, enfatizando todos los sonidos que contienen este combate. Dentro del ambiente sonoro, el cluster de cuerda hace las veces de leitmotiv. Según Montero la música «pareciera provenir de los alaridos de esta naturaleza saqueada sin piedad, así como anticipa las punzantes aristas de un relato teñido de principio a fin de violencia y de dolor» (2001, capítulo 4, sección 5, párrafo 26), y es esta textura musical de cuerda la que refleja este grito animal de la tierra, que volverá a quejarse cuando Plainview vuelve a cavar en ella para enterrar el cadáver de su falso hermano (Montero 2001, capítulo 4, sección 5, párrafo 26). George Toles considera que ese cluster es el elemento que va a hacer a Plainview perder la cabeza convirtiéndole en el ser ambicioso y sin escrúpulos que más tarde va a destapar (2016 capítulo 4, sección 1, sección 4). Se tome la opción analítica que más interese, se trata con un elemento musical que rompe la idea tradicional de leitmotiv al no ser una melodía, es una textura, un plano sonoro musical, y que refleja un verdadero sentimiento que va más allá de la significación de asociación simple. Se puede decir que este uso musical entra dentro del terreno simbólico y metafísico que se refería en la cita de Adorno.

La narrativa de las películas que forman parte de este análisis está basada en el enfrentamiento entre dos personajes, Daniel Plainview y Eli Sunday en Pozos de 
Ambición, Freddie Quill y Lancaster Dodd en The Master, Doc Sportello y «Big Foot» Bjornsen en Puro Vicio, y Reynolds Woodcock y Alma en El bilo invisible. Cada pareja de personajes representa dos formas opuestas de enfrentarse a los acontecimientos que suceden en cada una, y es de los choques entre los personajes de donde surge el impulso narrativo y el conflicto. En el caso de The Master, la música vuelve a utilizar el recurso de leitmotiv para marcar más claramente esta oposición y recrearla a lo largo de todo el metraje. En el arranque de la película, se asocia al personaje Freddie, mientras disfruta de sus últimos días en la guerra, una música en la que en su base suenan instrumentos de percusión y de cuerda en pizzicato que aportan un ritmo irregular, con aire danzarín al estilo de Béla Bartók pero sin asentarse en un metro fijo. Por encima suenan otros instrumentos de cuerda que realizan gestos rápidos con arco y una flauta que suena con un ligero toque asiático. Se vuelve otra vez a percibir que esta música no está basada en una melodía, sino en una textura sonora en la que se acumulan elementos. Freddie Quill representa al salvaje, un ser en el más puro estilo rousseauniano que se mueve por instinto y se sitúa al margen de las convenciones sociales. Esa música divertida, irregular y primitiva, se enfrenta a la que se asocia con el personaje de Lancaster Dodd, en el polo opuesto en lo que se refiere a perfil de carácter. Dodd es refinado, educado, carismático, pero a su vez esconde una cara cínica, manipuladora y siniestra, por lo que ve en Freddie la herramienta perfecta para poderla manifestar sin sentirse culpable. Greenwood retrata a Dodd con un acorde mayor que resuena en las cuerdas de forma brillante y que es continuado por un acorde disonante en el agudo que se va descomponiendo en pequeños movimientos en las cuerdas que van transformándolo en una textura desordenada que poco a poco crece hasta que desaparece. En algunos momentos tras la desaparición de esta textura el acorde mayor vuelve a aparecer para ser continuado de la misma forma. Otro leitmotiv que huye de lo melódico y nos presenta dos texturas instrumentales; por un lado, el acorde mayor con su respuesta y por otro la descomposición de este proceso hacia lo caótico. Así como sucedía con Freddie, Lancaster Dodd es representado a la perfección en su dimensión narrativa por esta música. El acorde mayor, solemne, representa su personalidad fuerte y su carisma, el resto presenta un claro contraste, una distorsión de ese acorde mayor que refleja lo disfuncional de su fachada. La descomposición del acorde refleja la oscuridad oculta de Dodd. Greenwood vuelve a utilizar el recurso del leitmotiv con una técnica similar a la utilizada en Pozos de ambición y con una intención de significado muy similar. La música va más allá de los rasgos psicológicos de los personajes que quedan ocultos a la cámara, refleja la esencia de la relación entre ellos, como bien muestra cuando acompaña la larga secuencia en la que Dodd, por medio de unos ejercicios de una alta manipulación intenta tranquilizar y de alguna forma domar a Freddie, para así poderle controlar. 
El compositor Leonard Rosenman hablaba de la música para cine que componía de forma atonal como lectora de las mentes de los personajes (Prendergast, 1991, p. 119), la música de Greenwood en este tratamiento de los leitmotiv llega mucho más lejos, superando incluso la mera psicología. Muestra significados internos a la acción que se encuentran más cerca de la idea en sí, de la esencia de la historia, de su ontología, que del momento psicológico por el que los personajes pasan en los momentos en los que la música se les aplica. Leitmotiv que se integran dentro de un estilo contemporáneo que huye «fetichismo de la melodía» (Adorno 2007, p. 18) que plaga la música tradicional.

\section{A PARTIR DE AQUÍ}

Muchos son los detalles que se pueden extraer de los usos musicales en estas cuatro películas, tantos que no hay suficiente espacio para tratarlos, por lo que este artículo abre la puerta a investigaciones más extensas que puedan dar cabida a todos ellos. La idea inicial era la de presentar puntos en común presentes en la música de las cuatro películas que definirían una nueva forma de componer música para cine de la que es responsable Jonny Greenwood. La personalidad creativa del compositor británico sumada a la forma de narrar de Paul Thomas Anderson aporta una nueva visión, que en el fondo no abandona completamente los usos tradicionales, aunque sí los reinventa para darles una nueva dimensión. La banda sonora funde sus elementos creando una unidad que pocas veces se ha logrado en el cine narrativo. A la vez, su fusión con la imagen provoca un efecto de imposibilidad de separarlas. Anderson concibe el cine como una globalidad, un conjunto de elementos que tienen que estar comunicándose a la perfección para conseguir que el visionado de sus películas sea algo más que eso, que sea una experiencia audiovisual. La utilización por parte de Greenwood de técnicas de lenguaje contemporáneo complementa esa experiencia al apelar a significados narrativos que están más allá del mero señalamiento de emociones. La música se sumerge en la profundidad del relato para mostrar al espectador su esencia y su sentido real más allá de lo que nos cuenta la imagen. En algunos momentos sale a la superficie y se conecta con las músicas sincronizadas para aportar unidad a la banda sonora global. Es entonces cuando la música incidental se vuelve más melódica y abandona las texturas y los planos sonoros que se forman por medio de la combinación de los elementos más vanguardistas, incluso en algunos momentos llega a jugar con ambas formas. El trabajo de Greenwood en las películas de Paul Thomas Anderson ha abierto la puerta a una nueva forma de entender la música para cine, una forma única que caracteriza estas aplicaciones, lo que no implica que pueda funcionar en otro tipo de relatos. 
JOSÉ SÁNCHEZ SANZ

JONNY GREENWOOD, LA INMERSIÓN PERFECTA EN EL CINE DE PAUL THOMAS ANDERSON

\section{REFERENCIAS BIBLIOGRÁFICAS}

Adorno, T. W., et al. (2007). Composición Para El Cine: El Fiel Correpetidor. Madrid: Akal. Brown, R. S. (2009). Overtones and Undertones: Reading Film Music. London: Univ. of California Press.

Chion, M. (1997). La Música en el Cine. Barcelona: Paidós.

Montero, F. J. (2011). Paul Thomas Anderson. Madrid: Ediciones Akal. Edición Kindle.

Porfirio, R. (2002). Miklós Rózsa (1907-1995). En R. Porfirio, A. Silver y J. Ursini, Film noir reader 3: interviews with filmmakers of the classic noir period (pp. 163-176). New York: Limelight.

Prendergast, R. M. (1991). Film Music - a Neglected Art: a Critical Study of Music in Films. W W Norton.

Toles, G. E. (2016). Paul Thomas Anderson. University of Illinois Press.

Walls, S. C. (2011). Why Is No One Talking about Jonny Greenwood's Excellent New Recording? Slate Magazine. Recuperado de https://slate.com/culture/2011/11/ jonny-greenwoods-popcorn-superhet-receiver-its-great-so-why-is-no-one-talkingabout-it.html

\section{AUDIOVISUALES REFERENCIADOS}

Anderson, P. T. (productor), Anderson, P. T. (director). (2017). El hilo invisible [DVD]. Estados Unidos: Focus Features.

Anderson, P. T. (productor), Anderson, P. T. (director). (2014). Puro vicio [DVD]. Estados Unidos: Warner Bros.

Anderson, P. T. (productor), Anderson, P. T. (director). (2012). The Master [DVD]. Estados Unidos: The Weinstein Company.

Anderson, P. T. (productor), Anderson, P. T. (director). (2007). Pozos de Ambición [DVD]. Estados Unidos: Paramount. 